\title{
Determining The Dynamic Properties of a Cutting Machine Tool Ram
}

\author{
Marcel Svagr, Frantisek Sedlacek \& Jiri Sika
}
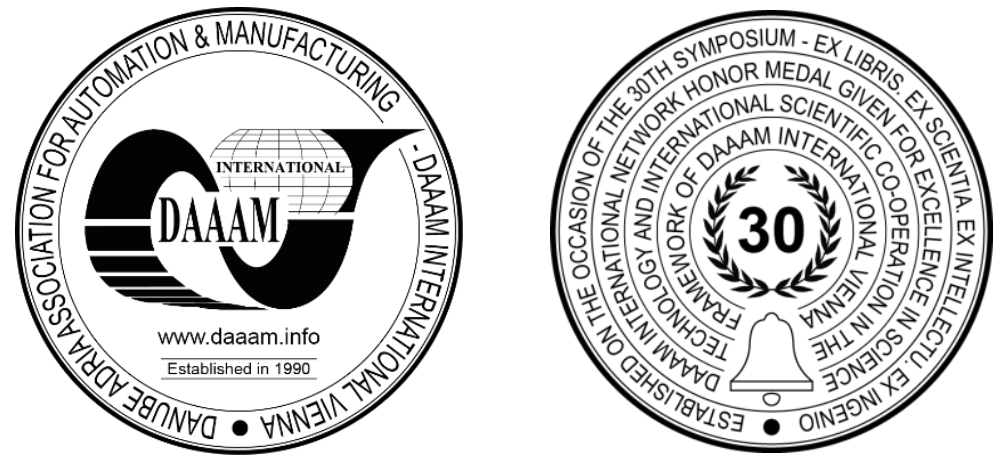

This Publication has to be referred as: Svagr, M[arcel]; Sedlacek, F[rantisek] \& Sika, J[iri] (2019). Determining the Dynamic Properties of a Cutting Machine Tool Ram, Proceedings of the 30th DAAAM International Symposium, pp.0929-0935, B. Katalinic (Ed.), Published by DAAAM International, ISBN 978-3-902734-22-8, ISSN 1726-9679, Vienna, Austria

DOI: $10.2507 / 30$ th.daaam.proceedings.129

\begin{abstract}
This work aims to determine the main dynamic properties of a cast ram in order to create correct modal numerical simulation in FEM software. The dynamic stability of machine tools is directly dependent on natural frequencies and their waveforms and it has large impact on the accuracy of machine tools during the cutting process. Therefore, determining main dynamic properties (vibrations - natural frequencies and their waveforms) is very important. The numerical simulation was done in Siemens Simcenter software with NX Nastran solver. Simulation was carried out as a free state solution. Experimental measurement was done to verify the calculated data. Experimental measurement was performed using the impulse excitation method with a modal sledge hammer. As well as the modal sledge hammer, we used a triaxial accelerometer and a generator module. Subsequently, the experimental modal analysis was done in PULSE19 software. Comparison of results was performed after measuring. Certain agreement was found between the experimentally measured data and data form numerical simulation.
\end{abstract}

Keywords: casting of ram; FEM; experimental modal analysis; impulse excitation method.

\section{Introduction}

Not only static forces but also dynamic forces can be applied to all structures, systems (machines). Since the effects of static forces are relatively well mapped nowadays, research into the dynamic properties of structures comes to the fore. Speaking of dynamic properties, it is mainly the natural frequencies and mode shapes of the system [1].

To determine these properties, modal analysis [11] can be used in FEM [12] software. This can be used during design of machine as well as for later validation of dynamic properties. Other possibilities for determination of natural frequencies and mode shapes is experimental modal analysis (modal testing), this can be used only at existing structure.

The aim of this work is create suitable numerical model based on real cast ram (its dynamic properties). The ram is one of the main parts (the most stressed as well) of top-gantry milling machine. 


\section{Theory}

\subsection{Modal analysis}

Modal analysis is the process of determining dynamic characteristics of a system in forms of natural frequencies, damping factors and mode shapes, and using them to create a mathematical model (FEM). The formulated mathematical model is known as the modal model of the system and its modal data are dynamic characteristics [1], [2].

Second order linear inhomogeneous differential equation (1) with constant coefficients $\boldsymbol{M}, \boldsymbol{B}, \boldsymbol{K}$ represents mathematical model of linear time invariant system with one degree of freedom. Where $\boldsymbol{M}$ is total mass matrix, $\boldsymbol{B}$ is total damping matrix, $\boldsymbol{K}$ is total stiffness matrix, $\boldsymbol{U}$ is generalized coordinate (deflection from static equilibrium position), $\boldsymbol{F}$ is generalized excitation force [3], [4].

$$
\boldsymbol{M} \cdot \ddot{\boldsymbol{U}}(t)+\boldsymbol{B} \cdot \dot{\boldsymbol{U}}(t)+\boldsymbol{K} \cdot \boldsymbol{U}(t)=\boldsymbol{F}(t)
$$

The FEM of free undamped oscillation (modal analysis simulation) is based on equation (1) where $\boldsymbol{F}(t)=0$ (without excitation force) and $\boldsymbol{B}=0$ (without damping force) - see equation (2) [4].

$$
\boldsymbol{M} \cdot \ddot{\boldsymbol{U}}(t)+\boldsymbol{K} \cdot \boldsymbol{U}(t)=0
$$

When a harmonic oscillation $\boldsymbol{U}=\overline{\boldsymbol{U}} \boldsymbol{e}^{\boldsymbol{i} \Omega \boldsymbol{t}}$ is substituted into equation (2) we get equation (3). Where $\overline{\boldsymbol{U}}$ is harmonic vibration amplitude column matrix and $\boldsymbol{\Omega}$ is angular frequency of oscillation [3].

$$
\left(\boldsymbol{K}-\Omega^{2} \boldsymbol{M}\right) \cdot \overline{\boldsymbol{U}}=0
$$

The natural frequencies result from the condition of zero determinants (4) [3].

$$
\operatorname{det}\left|\boldsymbol{K}-\Omega^{2} \boldsymbol{M}\right|=0
$$

The values of natural frequencies in FEM are usually given in the form of frequency $f$ [Hz] (5) [3].

$$
f=\Omega / 2 \pi
$$

It is not necessary to determine all natural frequencies and mode shapes from equation (3). A small amount of the lowest eigenvalues is sufficient, because there is the highest risk of collision with one of the excitation frequencies of the external load [5].

\subsection{Modal testing}

Modal testing is a process on a tested structure to obtain a mathematical description of the dynamic behaviour of the structure. FRF (Frequency response function) is created during measuring. FRF is basic of derived model (6).

$$
H(\omega)=\frac{\text { output }}{\text { input }}=\frac{\text { movemnet }}{\text { force }}=\frac{\text { response }}{\text { excitation }}
$$

There are 3 basic types of frequencies derived functions according to the derived parameter: deflection, speed, acceleration.

An element $\alpha_{j k}(\omega)$ represents a harmonic response at $x_{j}$ caused by a single harmonic force acting at another place $\left(F_{k}\right)$. $\lambda_{r}$ is eigenvalue of the r-mode, $\Phi_{j}^{r}$ is j-element of custom shape r-vector $\{\Phi\}$ (relative displacement at $j$-point when oscillating on $\mathrm{r}$-form), $\omega$ is the excitation angular frequency and $\mathrm{N}$ is number of modes [6], [7].

$$
\alpha_{j k}(\omega)=\frac{x_{j}}{F_{k}}=\sum_{r=1}^{N} \frac{\Phi_{j}^{r} \cdot \Phi_{k}^{r}}{\lambda_{r}^{2}-\omega^{2}}
$$

Equation (7) is basic of experimental modal analysis (modal testing) and shows direct connection between modal properties and response characteristic of the system. This equation confirms that it does not matter if the structure is excited at one point and the response is measured at all points (one column of the FRF matrix is measured) or the structure is excited at all points and the response is measured at one point (one row of the FRF is measured). In both cases after the composition we get the same FRF matrix [6], [7]. 


\section{Modal analysis}

First, was created idealise part (without screw holes, radiuses etc.) of ram. for numerical simulation. Then solution was set with parameters are given in the table 1. Idealise model was meshed with elements CTETRA (see Table 1 - FEM settings).

\begin{tabular}{|l|l|l|l|}
\hline \multicolumn{2}{|c|}{ FEM settings } & \multicolumn{2}{c|}{ Solution settings } \\
\hline Element Type: & CTETRA (10) & Solver: & NX Nastran \\
\hline Element Size: & $40 \mathrm{~mm}$ & Analysis Type: & Structural \\
\hline Number of elements: & 86258 & Solution Type: & 103 Real Eigenvalues \\
\hline Material: & Iron Cast G40 & Eigenvalue Method: & Lanczos \\
\hline
\end{tabular}

Table 1. Modal Analysis simulation parameters

Simulation was performed in NX Nastran solver with restriction $1-1600 \mathrm{~Hz}$ (max 40 modes). Boundary conditions represent free state, it mean there are no boundary conditions (Fig. 1). This is commonly known procedure how to get natural frequencies and mode shapes of free state structure [8].
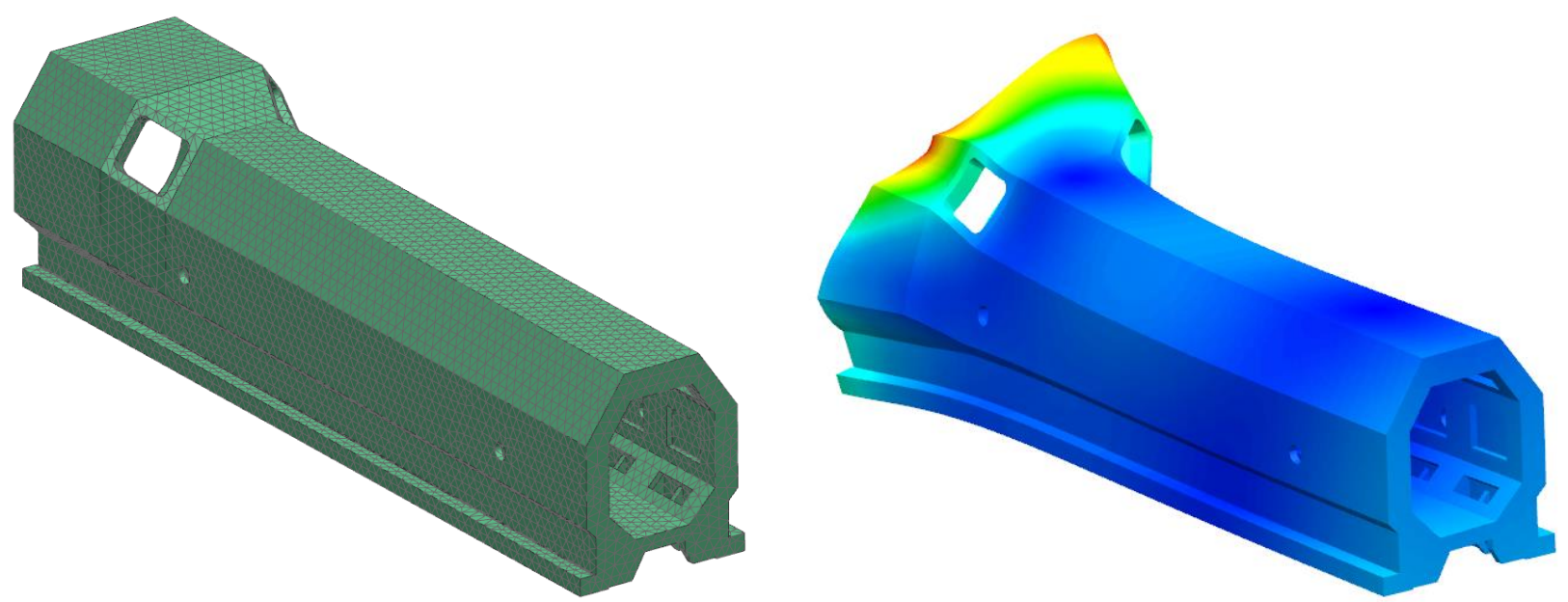

Fig. 1. FEM model (felt), 1st mode shape (right)

The calculation was terminated earlier than the $1600 \mathrm{~Hz}$ limit because 40 modes were previously found. The highest detected frequency is $1158.380 \mathrm{~Hz}$ within the specified range. This value is sufficiently high because the excitation frequencies for the ram are assumed to be low. The results of the modal analysis are shown in Table 2.

\begin{tabular}{|c|c|}
\hline Mode & Frequency $[\mathbf{H z}]$ \\
\hline 1. & 247.243 \\
\hline 2. & 256.382 \\
\hline 3. & 280.809 \\
\hline 4. & 287.823 \\
\hline 5. & 315.171 \\
\hline 6. & 394.501 \\
\hline 7. & 429.799 \\
\hline 8. & 465.812 \\
\hline 9. & 479.238 \\
\hline 10. & 497.127 \\
\hline$\ldots$ & $\ldots$ \\
\hline 40. & 1158.380 \\
\hline
\end{tabular}

Table 2. Modal analysis simulation results

Deformation of wider site of the ram represents mode shapes of frequency $247 \mathrm{~Hz}$ (1st mode) and frequency $288 \mathrm{~Hz}(4 \mathrm{th}$ mode). The bending mode shapes are evident at frequency $256 \mathrm{~Hz}$ (2nd mode) and frequency $281 \mathrm{~Hz}$ (3rd mode). Nearly clear torsion is displayed at frequency $315 \mathrm{~Hz}$ (5th mode). It is not possible to assign a shape of deformation (bending, torsion) that would correspond to the whole structure of the ram because of the dimension expansion at one end of the ram. 


\section{Experimental modal analysis (modal testing)}

Measurement was done at a cast ram, which hanged on ropes at a crane Fig. 2. Those boundaries were set to get as close as possible to free state (to avoid interference from adjacent structures) [9]. Experimental measurement was performed using modal sledge hammer TYPE 8208-003, triaxial accelerometer TYPE 4524-B, Generator module TYPE $3160+$ battery and signal processing was made in PULSE 19 program.

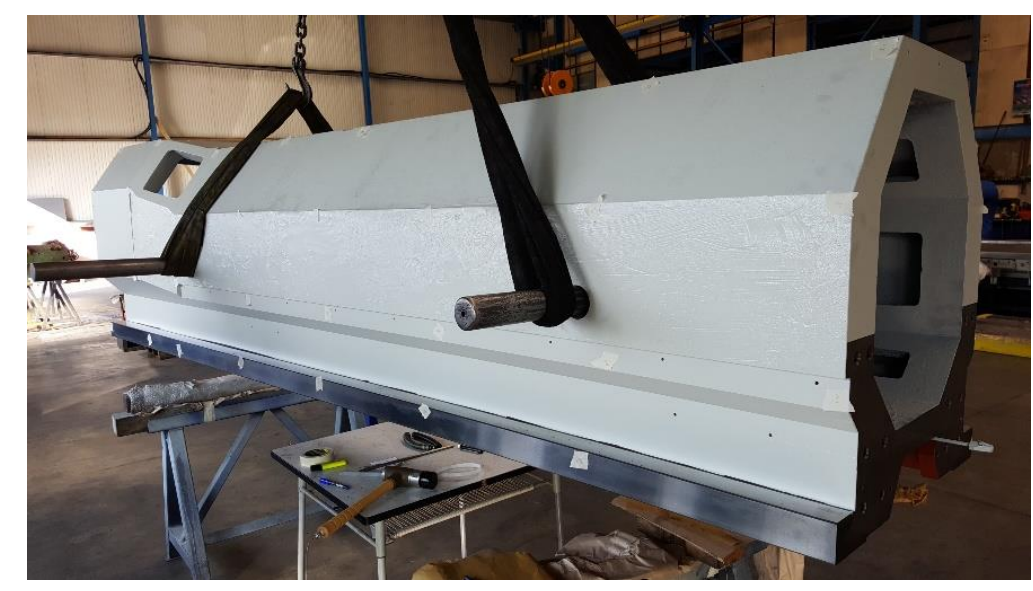

Fig. 2. The cast ram hanging on ropes at crane
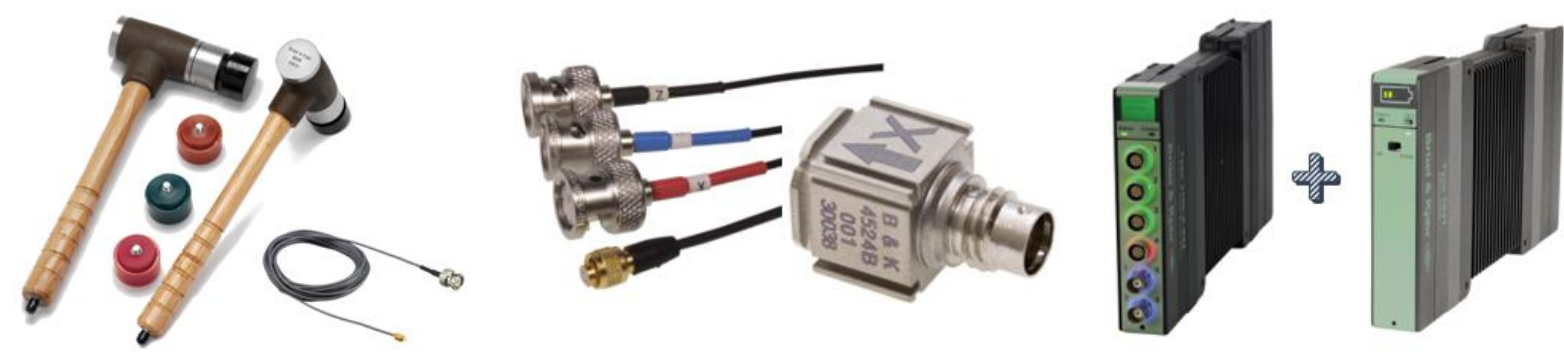

Fig. 3. Used Equipment: Modal Sledge Hammer, Triaxial Accelerometer, Generator Module + Battery (from right to left) [10]

A sensor (triaxial accelerometer) was placed at one point and an excitation was done at 63 points at the ram. Impact with modal sledge hammer into each point was repeated three times to eliminate mistakes of measurement. Response values were written in to the nodes of pre-prepared wireframe model (point model in PULSE 19 program). The basic measurement parameters are summarized in the Table 3.

\begin{tabular}{|l|l|}
\hline \multicolumn{2}{|c|}{ Measurement settings } \\
\hline Impact spots & 63 \\
\hline Count of sensors & 1 \\
\hline Type of sledge hammer head & Hard (black) \\
\hline Boundary & Hung on rope ("free-free state") \\
\hline Software & PULSE 19 \\
\hline Number of repetitions & 3 \\
\hline Restriction & $0-1600 \mathrm{~Hz}$ \\
\hline Step size & $1 \mathrm{~Hz}$ \\
\hline
\end{tabular}

Table 3. Basic conditions of measurement

The frequencies with pronounced amplitude at most measuring points were selected from the measured data. The first ten most significant frequencies are stated in the

Table 4. The results were transferred to the NX software for better graphical representation and direct comparison of measured and calculated values. 


\begin{tabular}{|c|c|}
\hline Mode & Frequency $[\mathbf{H z}]$ \\
\hline 1. & 238 \\
\hline 2. & 251 \\
\hline 3. & 314 \\
\hline 4. & 367 \\
\hline 5. & 401 \\
\hline 6. & 435 \\
\hline 7. & 476 \\
\hline 8. & 538 \\
\hline 9. & 673 \\
\hline 10. & 813 \\
\hline
\end{tabular}

Table 4. Modal test results ( $1^{\text {st }}$ ten most significant frequencies)

\section{Comparison and discussion}

Frequencies starts to more significantly differ from third mode (see Table 2 and Table 4). It is caused by that FEM modal analysis simulation shows every natural frequency without respecting intensity of oscillation (amplitude size). While the experimental measurement shows characteristically natural frequencies that appear in response to given excitation (impact with modal sledge hammer). Is necessary deeper research of mode shapes for better comparison between frequencies from experimental measuring and modal analysis simulation. In the Table 5 is five chosen frequencies which visually correspond to each other by mode shape. Respectively, first five natural frequencies which were found in experimental measurement were compared with frequencies from numerical simulation according to their mode shapes.

\begin{tabular}{|c|c|c|c|c|}
\hline \multicolumn{2}{|c|}{ Modal test results } & & \multicolumn{2}{c|}{ Modal analysis results } \\
\hline Mode & Frequency $[\mathbf{H z}]$ & Percent deviation $[\%]$ & Mode & Frequency $[\mathbf{H z}]$ \\
\hline 1. & 238 & 3.78 & 1. & 247 \\
\hline 2. & 251 & 1.99 & 2. & 256 \\
\hline 3. & 314 & 0.03 & 5. & 315 \\
\hline 4. & 367 & 7.63 & 6. & 395 \\
\hline 5. & 401 & 7.23 & 7. & 430 \\
\hline
\end{tabular}

Table 5. Comparison of values (Modal test/ Modal analysis)

Comparison of modal test mode shapes a modal analysis simulation mode shapes below:

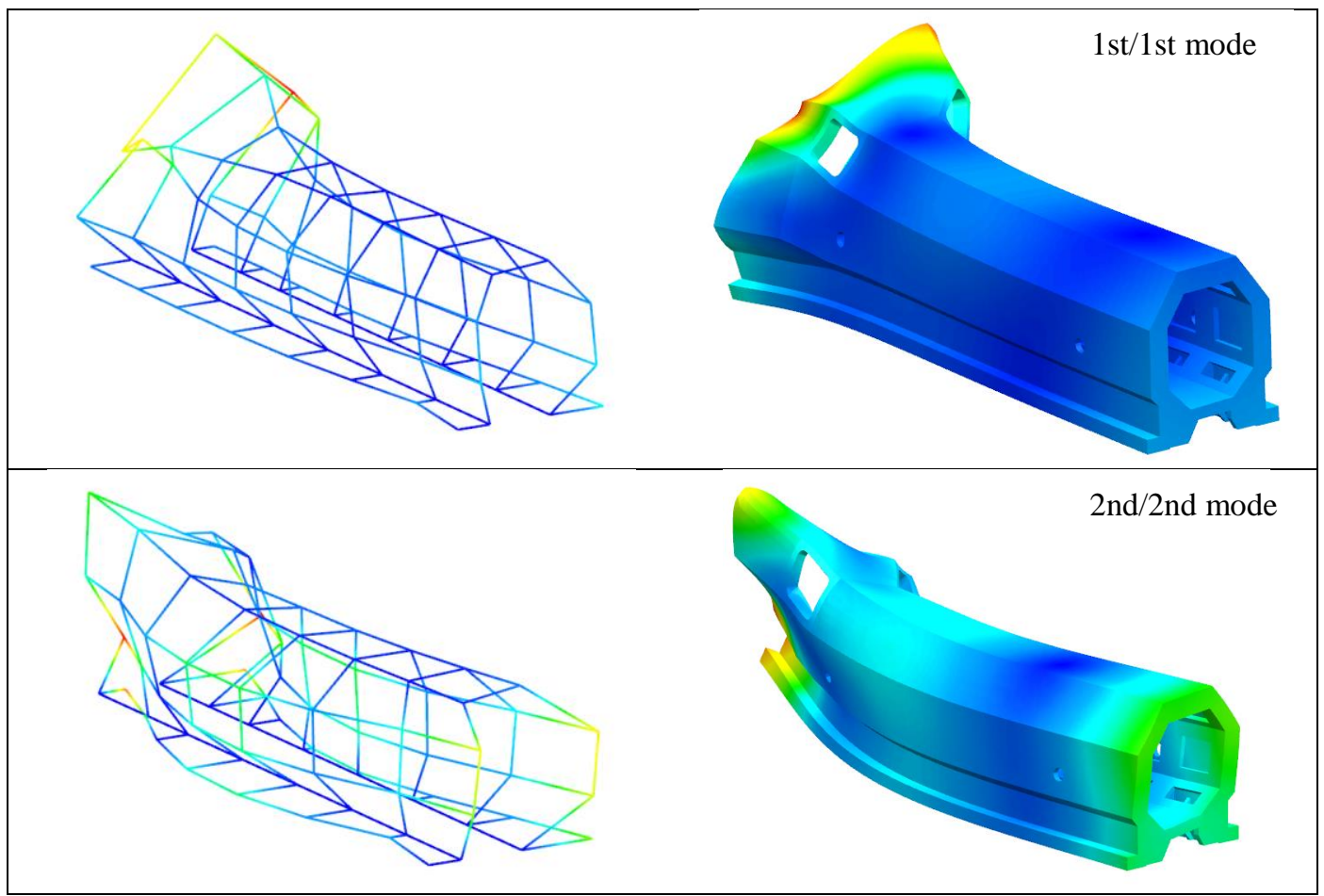




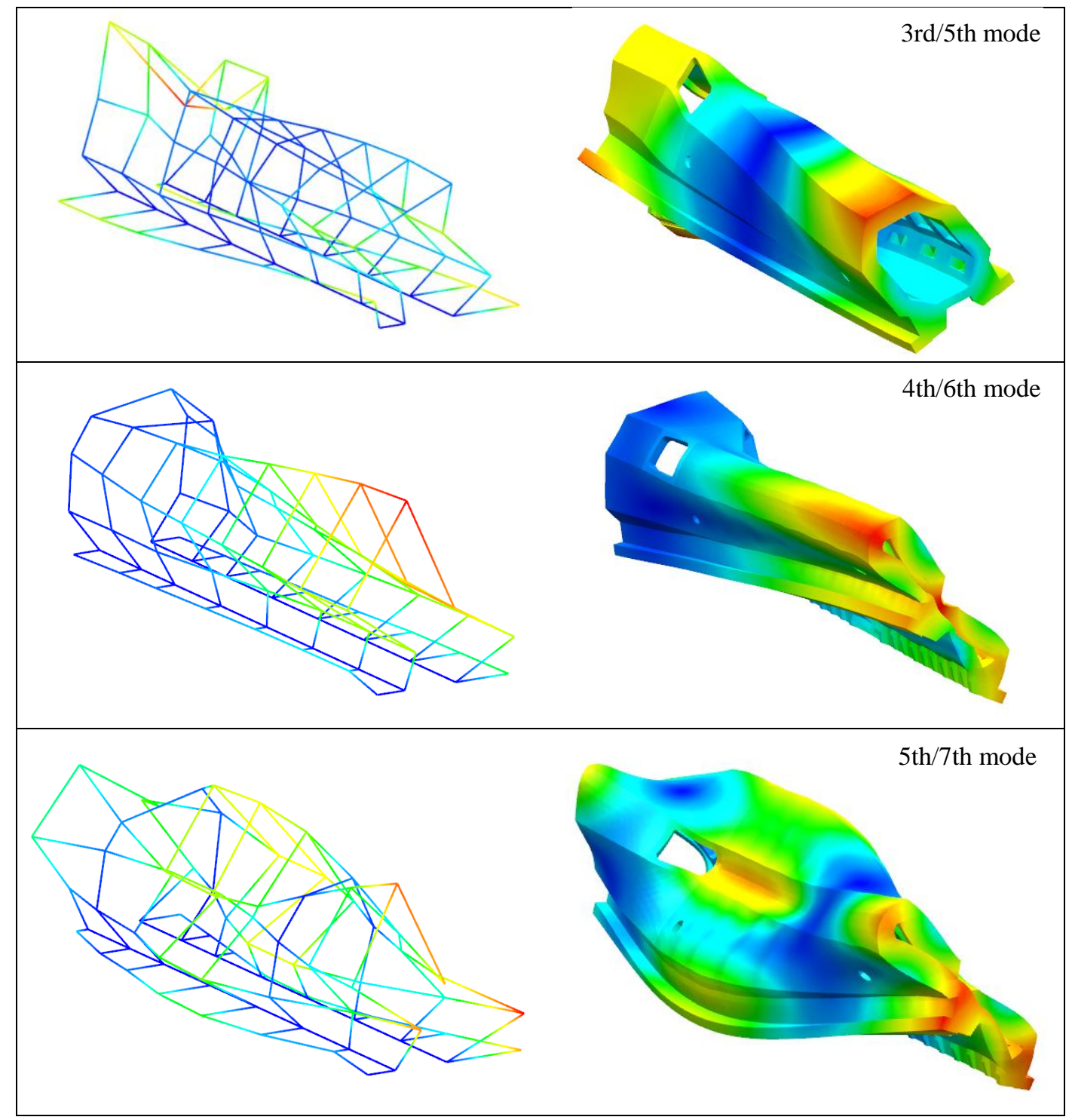

Table 6. Visual comparison of mode shapes

\section{Conclusion}

We were dealing with problem of determine dynamic properties of cast ram and the accuracy of the numerical model compared to the actual cast ram. In this work a FEM modal analysis simulation was performed on the cast ram of top-gantry milling machine as well as modal test (experimental modal analysis). Strong agreement was found between the experimentally measured data and data from the numerical simulation. Deviation does not exceed $8 \%$. It follows that numerical model can be considered correct. If the results were not compared, the error in the structure of the FEM model could be overlooked, or the defect or difference of the existing machine part could be overlooked.

The next step is correlate results based on mode shape to increase accuracy of compare results from modal analysis and modal test. Then the obtained results can be validated and FEM model could be modified according to measured data. If a good match is found and the model can be modified according to the existing part of the machine, then it gives more accurate data for further calculations (for static and dynamic properties of the whole machine).

\section{Acknowledgments}

This article has been prepared under project SGS-2019-001 (Complex Support of Design of Technical Equipment IV.) at the University of West Bohemia in Pilsen. 


\section{References}

[1] He, J.; Fu, Z-F. (2001). Modal Analysis, Butterworth-Heinemann, ISBN 978-0-7506-5079-3, Oxford, UK

[2] Avitabile, P. (2018). Modal Testing: A Practitioner's Guide, John Wiley \& Sons Ltd, ISBN 9781119222897, Hoboken, United States

[3] Zienkiewicz, O. C.; Taylor, R. L. (2000). The Finite Element Method, 5th ed., Butterworth-Heinemann, ISBN 075065055 9, Oxford, UK

[4] Zeman, V.; Hlaváč, Z. (2010). Kmitání Mechanických Soustav, University of West Bohemia,

ISBN 978-80-7043-337-9, Pilsen

[5] Cook, R. D. (1981). Concepts and Applications of Finite Element Analysis, J. Wiley, ISBN 978-0471356059, N.York

[6] Schwarz, B. J.; Richardson, M. H. (1999). Experimental Modal Analysis, Vibrant Technology, Inc. Jamestown, California 95327

[7] Hermans, L.; Van Der Auweraer, H. (2002). Modal Testing and Analysis of Structures under Operational Conditions: Industrial Applications, LMS International, Interleuvenlaan 68, B-3001, Leuven, Belgium

[8] Basic Dynamics Analysis User's Guide, Available https://docs.plm.automation.siemens.com/data_services/resources/nxnastran/10/help/en_US/tdocExt/pdf/basic_dy namics.pdf Accessed: 2019-10-01

[9] Wu, L.; Yang, Y.; Maheshwari, M. (2019). Location Identification of Line Supports Using Experimental Modal Analysis, Maritime Institute, Nanyang Technological University, Singapore 639798, Singapore

[10] Brüel\&Kjaer. Transducers and Conditioning, Available from: https://content.bksv.com/download-the-catalogue Accessed: 2019-10-01

[11] Zahalka, M. (2014). Modal Analysis of Hydraulic Press Frames for Open Die Forging. Proceedings of the 24th International DAAAM Symposium "Intelligent Manufacturing \& Automation", 23-26th October 2013, Zadar, Croatia, Volume 69-2014, ISSN 1877-7058, Katalinic, B. (Ed.), pp 1070 - 1075, Published by Elsevier Ltd., Vienna, 2014, DOI: 10.1016/j.proeng.2014.03.092.

[12] Elmedin, M.; Vahid, A.; Nedim, P.; Nedžad, R. (2015). Finite Element Analysis and Experimental Testing of Stiffness of the Sarafix External Fixator. Proceedings of the 25th International DAAAM Symposium "Intelligent Manufacturing \& Automation", 26-29th November 2014, Vienna, Austria, Volume 100-2015, ISSN 1877-7058, Katalinic, B. (Ed.), pp 1596 - 1607, Published by Elsevier Ltd., Vienna, 2015, DOI: 10.1016/j.proeng.2015.01.533 